\title{
Pervasive development disorder explained by the theory of executive dysfunction: case study
}

\author{
Anna Martha Vaitses Fontanari ${ }^{1}$ and Vivian Denise Cazerta Vaitses ${ }^{2}$ \\ 1 - Federal University of Rio Grande do Sul, Porto Alegre, RS, Brazil. \\ 2 - Neuro Sapiens, Center for Cognitive Neurophysiology, Porto Alegre, RS, Brazil
}

\begin{abstract}
A case of a hyperactive child with impaired speech, perceptual-motor capacity and interpersonal skills is presented. Presumptive diagnoses are discussed according to the international classifications most often used. The nature of pervasive developmental disorders is examined based on the concepts of theory of mind and theory of executive dysfunction. Keywords: pervasive developmental disorder, theory of mind, theory of executive dysfunction.
\end{abstract}

Received 15 February 2011; received in revised form 31 July 2011; accepted 6 September 2011. Available on line 10 October 2011

\section{Introduction}

The International Statistical Classification of Diseases and Related Health Problems (ICD) and Diagnostic and Statistical Manual of Mental Disorders (DSM) are international classifications frequently used for neuropsychiatric diagnoses in childhood and adolescence. Among their mental disorders, the most complex in both the ICD and DSM are the pervasive developmental disorders Autism and Asperger Syndrome because of the diversity of explanations of causal mechanisms. Explanations for the causes of these disorders range from purely emotional factors to exclusively cognitive factors. The following are four approaches that we have chosen for discussion in this report.

\section{Psychoanalytic}

This theory attributes autism to a lack of parental investment in the dimension of desire and narcissistic completeness (Zamo \& Paiva, 2007). If the functions of projecting an idealized image and pre-conceived notion in the infant are not present, then he/she does not enter the symbolic world and becomes a person without a consistent self, which is the predominant characteristic of psychotic mental disorders (Jerusalinsky, 1984; Tustin, 1990).

Anna Martha Vaitses Fontanari, Federal University of Rio Grande do Sul, Genetics Department, Porto Alegre, RS, Brazil. Vivian Denise Cazerta Vaitses, Neuro Sapiens, Center for Cognitive Neurophysiology, Porto Alegre, RS, Brazil. Correspondence regarding this article should be directed to: Anna Martha Vaitses Fontanari, Neuro Sapiens, Center for Cognitive Neurophysiology, Dom Feliciano 78, Porto Alegre, RS 90020-160 Brazil. Phone: +55 51322466 98. E-mail: vivian.vaitses@ufrgs.br

\section{Affective-biological}

This is an intermediary approach that concerns the concept of attachment. In this theory, an autistic child is born with a biological inability to establish emotional connections and feel emotions like love, affection, friendship, and loyalty (Bowlby, 1998; Hobson, 1993).

\section{Theory of mind}

The theory of mind is a cognitive neuropsychological approach that explains autism as an inability to construct a hypothesis about what the person who tries to establish a contact feels, thinks, or wants. Although situated in a cognitive category, this concept cannot be detached from the concept of emotion-affect because empathy is underpinned by the desire to interact (Zald \& Andreotti, 2010).

\section{Executive dysfunction}

The executive dysfunction approach argues that the autistic child does not possess the mechanism that selects the relevant stimulus and inhibits others. Therefore, the child is simultaneously confronted by all of these sensory events around him (Bosa, 2001). Evidence indicates that autism is a disorder of the association cortex, both of its neurons and projections (Pelicano, 2007). In particular, it is a disorder of connectivity that appears to primarily involve intrahemispheric connectivity (Minshew \& Williams, 2007).

In this case report, we discuss the diagnostic difficulties of situations in which symptoms of various mental disorders coexist, impairing the selection of a primary diagnosis and consequently limiting the identification of the underlying etiopathogenic nature of the case. We also discuss a specific explanatory 
theory for autism that encompasses both cognitive and affective aspects. This theory posits that the autistic individual is unable to develop a theory of mind because of a disturbance in executive function that causes indiscriminate sensory stimuli and an inability to organize and manage these stimuli (Bosa, 2001).

\section{Case report}

A 5.5-year-old girl (VF) was referred by her school for speech and neurological evaluation because of signs of delayed speech development and perceptual-motor dysfunction. VF was the only child of a couple in a stable relationship. She went to elementary school in the morning and stayed home with her mother in the afternoon. The child always came to the meetings with her father, who said that the mother had anorexia nervosa and could not attend the meetings. Some family information may have been kept confidential. No other similar case or reference to mental or neurological disease was identified in the family. The father indicates, however, that a maternal aunt was very hyperactive during childhood, and perhaps her behavior resembled that of VF. Obstetric events were uncomplicated, and the girl exhibited no significant history of disease.

The assessment of VF was performed during two appointments. Only the father attended the third meeting to obtain the results. The evaluation method included free observation, physical and neurologic examination, evolutional neurologic examination (ENE), and the application of Piagetian tasks and neuropsychological tests. The only examination that was normalized and standardized for our population was the ENE. Therefore, the other findings were only descriptive, leading to conclusions based solely on the author's experience.

VF's speech was characterized by phonetic deviations, phonological disorders, and articulatory defects that resembled the speech of a deaf person. Her language was predominantly contextualized but poor in vocabulary, with short sentences that consisted of predominantly verbs and nouns. On several occasions, she verbalized fragmented, decontextualized sentences with inappropriate intonation and echolalia.

Her behavior was hyperactive, and her attention was hyperalert. Her affect had characteristics that were unconventional. Some connections appeared to be present but fleeting. The aspects of attention and hyperactive behavior were more important than an affective disorder in the formation of her bonds. Importantly, delusional thoughts or hallucinations cannot be completely discarded. Furthermore, the patient exhibited shared attention but did not show an understanding of false beliefs in the Unexpected Contents Task and Maxi Task.

In the praxis activities and traditional gnosis evaluated by development examination, VF showed a lag in performance of approximately 1 year in relation to her chronological age, with the exception of evidence of motor persistence, in which she failed to succeed for 4 years.

Especially in the ENE, she demonstrated mild difficulty following performance in the evaluation of fine motor skills, coordination, and visuomotor diadochokinesia. She struggled in the gnosis of color test (normal motor persistence and static equilibrium). Finally, she was normal in dynamic equilibrium.

In the Piagetian Tasks, she exhibited the following profile. She did not present a conservation of numbers. She was able to count to 5 but did not make the relation between quantity and numeral except 1 and 2. In ranking, she used trial and error in an unsystematic manner. Other parameters of the protocol did not apply to the patient's age (e.g., conservation of length, conservation of mass, quantification with inclusion classes, dichotomies with changing criteria, proportionality, probability and logical connections, questions with inferences and logical structure or formal reasoning based on the conceptual object). Electroencephalographic and computed tomography scans were normal.

\section{Discussion}

The diagnosis of a mental disorder is derived primarily from the observable behavior of the patient. Behavior is the expression of the biological constitution of the brain that is constructed through the interaction of innate components with the environment. In this particular case, behavior was evaluated through its manifestations in language and neuropsychological function such as language, speech, sustained attention, selective attention, conduct, praxis, gnosis, and theory of mind. Memory function, however, was not directly tested.

Language is the main resource of interpersonal communication. It begins before birth when, without exactly aiming for a communicative act, the fetus moves in response to a maternal event. The mother, in turn, gives meaning to the gesture of the baby, and then the gesture becomes a communicative signal (i.e., a primordial form of language). Explaining a congenital disorder of language by the kind of significance that the first teacher of this function, the mother, gives to the infant's signals is reasonable. If the mother is a carrier of a mental disorder that interferes with her interpretation of the infant's behavior, then confused language may result between them. The reverse is perfectly justifiable. If the baby has a biological impairment that prevents it from establishing communication along the lines of its kind, it becomes very difficult or impossible for the listener to give meaning to its gestures or signals. VF had verbal and gestural language or communication that was different from what is commonly observed in children her age. 
A key issue in the patient's diagnosis is directly related to the differential diagnosis between a language disorder and autistic spectrum disorder. A clinical framework of mixed dysphasia could explain the decontextualization in her speech. Delusions or hallucinations could confirm a psychotic disorder. Echolalia and inadequate intonation are part of the repertoire of psychotic symptoms, including autism but not aphasia.

VF exhibited phonetic and phonological deviations in the category of verbal language. The first deviation was represented by the incorrect placement of buccofacial constituents, and the second deviation was represented by changes in central representations of phonemes.

Hyperactive behavior is compatible with both a primary framework of language disorder and affective disorder. Likewise, a predominantly hyperalert state of awareness may be attributable to neurological or psychological aspects (or both). Using a neuropsychological approach, Lau, Rogers, Ramnani, and Passingham (2004) attributed the attention regarding the selection of "desired action" to area 46 (i.e., the dorsal prefrontal cortex). In the same article, James (1890) is cited as the author who defined the term "desired action" as "consciously paying attention to their selection." When monitoring the conflict between the selected options, the anterior cingulate cortex and presupplementary motor area are predominantly activated (Botvinick, Braver, Barch, Carter, \& Cohen, 2001). This activity involves working memory (Petit, Courtney, Ungerleider, \& Haxby, 1998). However, regarding attentional aspects, the theory of executive dysfunction is especially important for explaining autism. When confronted with a bombardment of sensory stimuli, the patient's attention is lost and diluted in a permanent switch that is more simultaneous than sequential among all outbreaks worthy of attention (Bosa, 2001). This circumstance leaves the individual puzzled, uncertain, resistant to change, and averse to unpredictable physical contact, all of which characterize the behavior of an autistic individual. Thus, hypervigilance accurately expresses the consequences of executive dysfunction.

The etiological theory of executive dysfunction may explain VF's symptoms in all of its dimensions. The interpretation of stimuli that reach the prefrontal cortex is compromised because of a failure in the control of parietal selective inhibition. Therefore, sustaining affect and the attention appropriate for the context becomes impossible.

\section{Conclusion}

The interaction between affect and cognition in the etiology of autism is consistent and unlikely to be refuted. The attempt to justify the autistic symptoms using a purely cognitive pole or exclusively emotional cause dichotomizes a single entity whose clinical manifestation is multifactorial. It is a Cartesian dualistic vision of simplifying the concept. The explanatory theory of executive dysfunction covers the range of deviations of global development because it does not deny the coexistence of the autistic manifestations in all areas of neuropsychological development.

\section{References}

Bosa, C.A. (2001). As relações entre autismo, comportamento social e função executiva. Psicologia: Reflexão e Crítica, 14, 281-287.

Botvinick, M.M., Braver, T.S., Barch, D.M., Carter, C.S., \& Cohen, J.D. (2001). Conflict monitoring and cognitive control. Psychological Review, 108(3), 624-652.

Bowlby, J. (1998). El apego (el apego y la perdida I). Barcelona: Paidos Iberica.

Hobson, R.P. (1993). Autism and the development of mind. Hove: Lawrence Erlbaum.

James, W. (1890). The principles of psychology. New York: H. Holt.

Jerusalinsky, A.N. (1984). Psicanálise do autismo. Porto Alegre: Artes Médicas.

Lau, H.C., Rogers, R.D., Ramnani, N., \& Passingham, R.E. (2004). Willed action and attention to the selection of action. Neuroimage 21, 1407-1415.

Minshew, N.J., \& Williams, D.L. (2007). The new neurobiology of autism: cortex, connectivity, and neuronal organization. Archives of Neurology, 64, 945-950.

Pelicano, E. (2007). Links between theory of mind and executive function in young children with autism: clues to developmental primacy. Developmental Psychology, 43, 974-990.

Petit, L., Courtney, S.M., Ungerleider, L.G., \& Haxby J.V. (1998). Sustained activity in the medial wall during working memory delays. Journal of Neuroscience, 18, 9429-9437.

Tustin, F. (1990). Barreiras autistas em pacientes neuróticos. Porto Alegre: Artes Médicas.

Zald, D.H., \& Andreotti, C. (2010). Neuropsychologia, 48, 3377-3391.

Zamo, R., \& Paiva, S. (2007). Language and autism: facts and controversies. Paper presented at the Course of Specialization in Neuropsychology. Porto Alegre: UFRGS. 